\title{
Effects of Vibration Amplitude on Microstructure Evolution and Mechanical Strength of Ultrasonic Spot Welded Cu/Al Joints
}

\author{
Jian Liu ${ }^{1}$, Biao Cao ${ }^{1, *}$ and Jingwei Yang ${ }^{2}$ \\ 1 School of Mechanical and Automotive Engineering, South China University of Technology, \\ Guangzhou 510640, China; ljxtu1989@163.com \\ 2 School of Mechatronics Engineering, Foshan University, Foshan 52800, China; mejwyang16@163.com \\ * Correspondence: mebcao@scut.edu.cn
}

Received: 28 August 2017; Accepted: 31 October 2017; Published: 2 November 2017

\begin{abstract}
The effects of vibration amplitude on the interface reaction and mechanical strength of the $\mathrm{Cu} / \mathrm{Al}$ joints were systematically investigated in ultrasonic spot welding (USW) experiments. The appropriate vibration amplitude $(22.5 \mu \mathrm{m})$ was beneficial for obtaining a sound joint. The formation of the continuous intermetallic compounds (IMC) layer accelerated with a higher vibration amplitude. The lap shear tensile strength of the $\mathrm{Cu} / \mathrm{Al}$ joints decreased when the thickness of the intermetallic layer was greater than $1 \mu \mathrm{m}$ at various amplitudes. With the increase in welding time, a crack occurred in the copper side owing to the occurrence of the eutectic reaction, $\alpha-A l+\theta \rightarrow L$, at the periphery of the nugget. The remarkable decline of ultrasonic power curves occurred at various amplitude levels upon the formation of a crack in the copper side.
\end{abstract}

Keywords: ultrasonic spot welding; vibration amplitude; intermetallic compounds; ultrasonic power

\section{Introduction}

The joints of dissimilar metals have many potential applications in many industries due to their reduced weight and economic advantages [1]. Dissimilar joints between aluminum alloys and copper are widely used in the battery packs and electronics industry because of their higher corrosion resistance and their electrical and thermal conductivities [2,3]. The joining of aluminum alloy and copper is also highly significant in cable systems owing to the lower weight and price of aluminum alloys [4]. However, due to the marked discrepancy in the thermal and mechanical properties and the rapid development of intermetallic compounds, traditional fusion welding methods are confronted with a difficult situation during the dissimilar joining of aluminum alloy and copper. Thus, increasing attention has been given to solid state welding methods, such as friction stir welding (FSW) and ultrasonic spot welding (USW). It is demonstrated that FSW has great potential in the production of high-performance $\mathrm{Cu} / \mathrm{Al}$ joints due to the low processing temperature [5-8]. Compared to friction stir spot welding, in this method, a sound joint is produced by ultrasonic spot welding with a shorter bonding cycle $[4,9,10]$. Furthermore, ultrasonic spot welding is more suitable for achieving satisfactory joints when working with miniature workpieces and multiple dissimilar materials owing to its characteristics [2,11,12].

Although USW has been applied for wire bonding and metal foils joining since the 1950s [13], only recently has it been used to join thicker metal sheets owing to the occurrence of high power USW. More recently, several studies were focused on thick dissimilar metal combinations, such as Al-Mg, $\mathrm{Al}-\mathrm{Cu}$ and Al-Fe in electric vehicle applications [2,13,14]. Tensile lap-shear tests have become the common criteria to evaluate the mechanical properties of welded joints. Scientific quality guidelines have not been established for a defect-free joint with high tensile strength. Besides, it is well known that 
the quality of an ultrasonic welded joint is quite sensitive to the variation of welding parameters, such as frequency, vibration amplitude, clamping force and welding energy [15]. Naturally, the interactions among these parameters have a great influence on the mechanical performance of the joints. As the vibration frequency reaches $20 \mathrm{kHz}$, the high strain rates $\left(10^{3}-10^{5} \mathrm{~s}^{-1}\right)$ can be achieved in a moment, owing to the interface interaction between the welded samples [16]. The relationship between the shear strain rate and the vibration amplitude is given in [17]:

$$
\gamma^{\prime}=\frac{2 f A}{h_{0}}
$$

where $f$ is the vibration frequency, $h_{0}$ is the reduced thickness of the nugget, and $A$ is the vibration amplitude. Consequently, the vibration amplitude is an important welding parameter that is correlated with the power and energy and affects both the shear strain rate and the plastic deformation. The energy input $(E)$ is proportional to the square of the vibration amplitude $(A)$ [16]. A moderate clamping force is indispensable to generate intimate contact between the welded samples. Generally, a high power level is required for extensive deformation associated with high clamping force. A feedback system controls the power output to maintain the welding tip in the high-frequency cyclical movement at the set vibration amplitude.

For ultrasonic spot welding, the effects of input energy/clamping force on the bonding quality of the joints have been reported in detail $[2,13,18]$. For instance, Zhao and Yang et al. studied the influence of input energy on the bonding behavior of $\mathrm{Cu} / \mathrm{Al}$ joints [2,11]. The function of the intermetallic thickness as welding energy was investigated by Panteli and Robson et al. [13,19]. The effects of welding energy and clamping forces on the microstructure of the Al-Fe joints were reported by Shakil [15]. It could be concluded that sound dissimilar metal joints were obtained by adjusting the energy input and the clamping force. However, few reports were made on the important role that the vibration amplitude played in dissimilar metal joints during high-power ultrasonic welding. Therefore, the main objective of the current research was to thoroughly clarify the effects that the vibration amplitude has on the $\mathrm{Cu} / \mathrm{Al}$ joints during high-power ultrasonic welding. The changes of intermetallic compounds, tensile strength and ultrasonic power were studied with welding time at various amplitude levels. The correlation between the generation of cracks in the copper layer and the variation of ultrasonic power has been revealed; this correlation could be beneficial for defects monitoring and the production of a defect-free joint.

\section{Materials and Methods}

In this study, $0.8 \mathrm{~mm}$ thick copper sheet and $0.8 \mathrm{~mm}$ thick 5652 aluminum alloy sheet (composition in wt \%: Al-2.02Mg-0.4(Si + Fe)-0.28Cr-0.04Mn-0.01Cu-0.01Zn) were lap-welded without prior surface cleaning or treatment. The welds were conducted using a lateral drive Telsonic M5000 system (Telsonic, Bronschhofen, Switzerland). The schematic diagram of the system is shown in Figure 1a. For all experiments, the copper samples were on the top, touching the sonotrode tip, and the aluminum samples were placed on the bottom anvil, as shown in Figure $1 \mathrm{~b}$. The sheets were processed into rectangular samples of $25 \mathrm{~mm}$ width and $70 \mathrm{~mm}$ length. The welds were conducted at the center of the $25 \mathrm{~mm}$ overlapped position. The knurled pattern of the sonotrode is shown in Figure 1c. According to the screening tests conducted before this experiment, different welding times (0.3-1.3 s) and amplitudes (80\%, 90\% and 100\%) were adjusted by using an ultrasonic welder (Telsonic, Bronschhofen, Switzerland). Detailed experimental parameters are shown in Table 1. In addition, for a better understanding of the intermetallic growth, isothermal annealing treatments were performed on the lightly welded aluminum to copper samples $(0.4 \mathrm{~s}$ and $22.5 \mu \mathrm{m})$ at $360^{\circ} \mathrm{C}$ for $1-32 \mathrm{~h}$. 


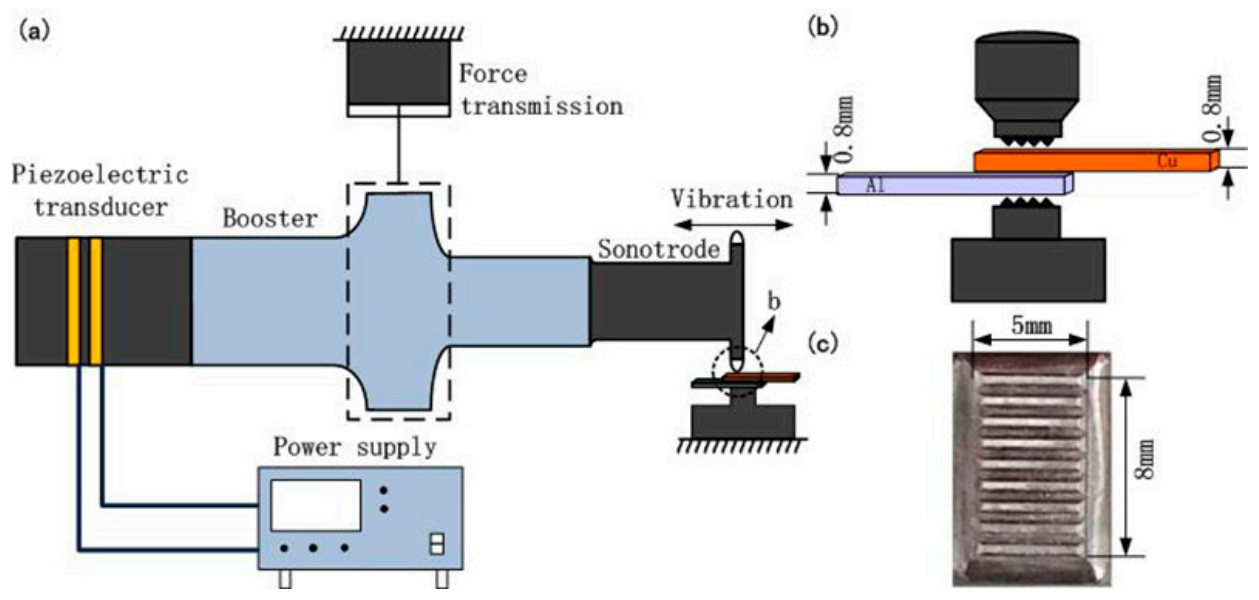

Figure 1. (a) A schematic diagram of the ultrasonic welding system, (b) partial enlargement and (c) knurl pattern of the sonotrode.

Table 1. Detailed welding parameters.

\begin{tabular}{cccc}
\hline Amplitude $A / \mu \mathrm{m}$ & Welding Time $\mathbf{T} / \mathbf{s}$ & Clamping Force $\boldsymbol{F} / \mathbf{N}$ & Frequency $f / \mathbf{k H z}$ \\
\hline 25 & $0.3-0.7$ & 1975 & 20 \\
22.5 & $0.4-1.0$ & 1975 & 20 \\
20 & $0.8-1.3$ & 1975 & 20 \\
\hline
\end{tabular}

The weld interfaces, which were transversely sectioned and parallel to the ultrasonic vibration direction, were characterized using a scanning electron microscope equipped with an energy dispersive spectrometer (Quanta 200, FEI, Eindhoven, The Netherlands). Tensile lap shear tests were conducted on the welded samples using a CMT5105 testing machine (MTS China Co., Ltd., Shenzhen, China) at a cross-head speed of $1 \mathrm{~mm} / \mathrm{min}$. The $\mathrm{Cu} / \mathrm{Al}$ joint failure always occurred along the interface. Consequently, the phase constituents on the tensile fracture surfaces of the $\mathrm{Cu} / \mathrm{Al}$ joints were investigated with X-ray diffraction (XRD, D8-Advance, Bruker, Germany). Vickers microhardness tests of the $\mathrm{Cu} / \mathrm{Al}$ joints were measured diagonally across the welding interface with a load of $25 \mathrm{~g}$ and a dwell time of $15 \mathrm{~s}$. The interface temperature was measured using a K-type thermocouple with a diameter of $0.25 \mathrm{~mm}$. The thermocouples were inserted into the aluminum sheets along the groove, which was precisely processed to ensure that the temperature measurements were determined on the weld center. Real-time dynamic measurements on the vibration of the sonotrode tip were performed with a sampling frequency of $392 \mathrm{kHz}$ using a LK-G5001 laser displacement sensor (KEYENCE, Osaka, Japan). The temperature and vibration data were recorded using the data acquisition system based on the NI-6133 (National Instruments, Austin, TX, USA). The different vibration amplitudes $(80 \%, 90 \%$ and $100 \%$ ) corresponded to $20,22.5$ and $25 \mu \mathrm{m}$, respectively.

\section{Results and Discussion}

\subsection{Microstructure Evolution}

The microstructural evolution of the welding interface at the weld center was investigated by scanning electron microscopy. The joints began with the microbond formation at the asperities, where the oxides were removed first because of the fretting friction between the copper and the aluminum sheet [19]. Subsequently, the intermetallic compounds nucleated with diffusion across the microbonds, and intermetallic islands were formed [19]. With the increase in welding time, a continuous intermetallic layer was formed due to the inter-impingement of neighboring islands [13]. Once the layer was formed, the diffusion through the intermetallic layer occurred. The thickness of the intermetallic layer then increased with the welding time, as illustrated in Figure 2. 

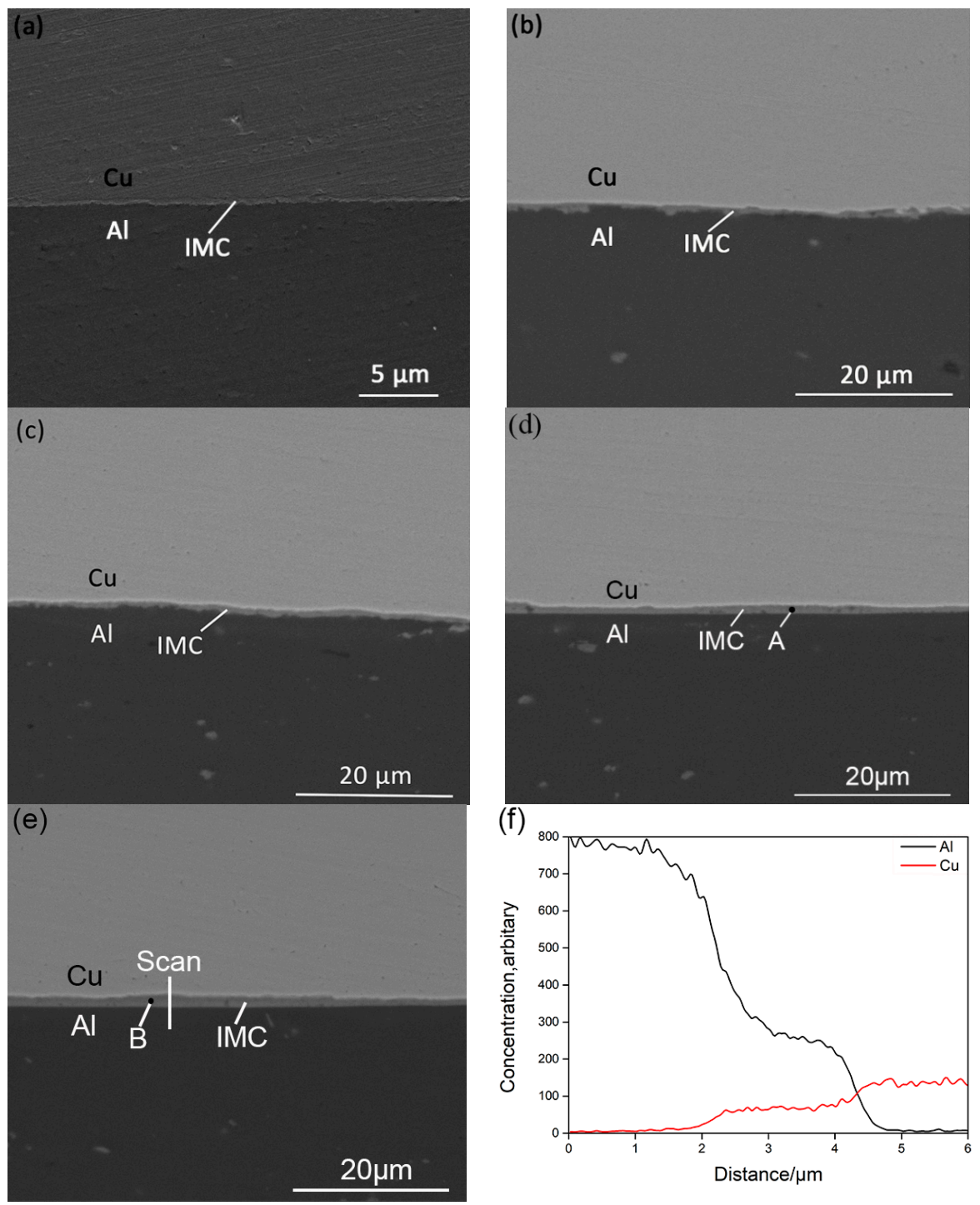

Figure 2. Scanning electron microscopy observations of the welding interface for the amplitude of $22.5 \mu \mathrm{m}$ at welding times of (a) $0.6 \mathrm{~s}$, (b) $0.7 \mathrm{~s}$, (c) $0.8 \mathrm{~s}$, (d) $0.9 \mathrm{~s},(\mathbf{e}) 1.0 \mathrm{~s}$ and (f) energy dispersive spectroscopy (EDS) linescanning across the intermetallic compound (IMC) layer at $1 \mathrm{~s}$.

The atomic content of the IMC phases was measured by energy dispersive spectroscopy (EDS). The results showed that the atomic contents of the gray phase in regions A (Figure 2d) and B (Figure 2f) are $70.12 \mathrm{Al}-29.88 \mathrm{Cu}$ and $72.93 \mathrm{Al}-26.73 \mathrm{Cu}($ at $\%)$, respectively. A plateau stage could be observed as the EDS linescanning across the intermetallic layer in Figure 2f, which suggested that the IMC layer consisted of a single phase. Since the copper substrate suffered from more severe plastic deformation, a higher concentration of lattice defects was generated. As a consequence, a large number of aluminum atoms diffused through the intermetallic layer from the aluminum substrate to the copper substrate. It was inevitable that the aluminum atoms were trapped inside the intermetallic compounds once the welding was terminated, which led to a higher aluminum content than the real IMC phase.

To further identify the intermetallic phase, the XRD spectra of the fractured surfaces of the $\mathrm{Cu} / \mathrm{Al}$ joints were obtained (Figure 3). It was found that the IMC phase consisted mainly of $\mathrm{CuAl}_{2}$, consistent with the findings reported by Yang et al. and Fujii et al. [2,20]. A small quantity of CuAl was also detected. Therefore, it could be concluded that the main IMC phase was $\mathrm{CuAl}_{2}$, based on the XRD spectra and EDS. 

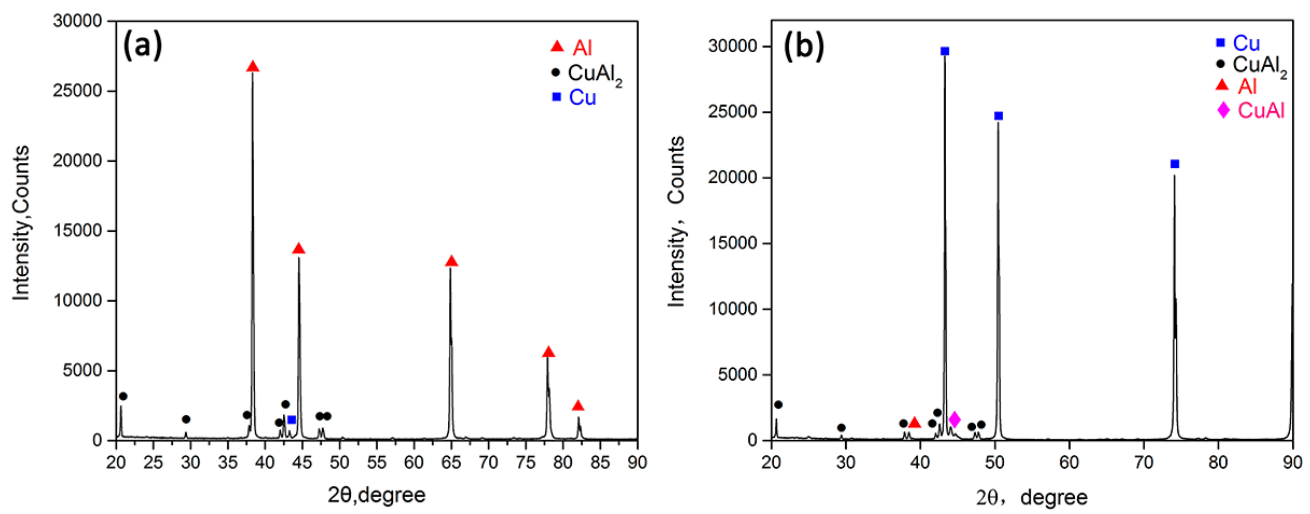

Figure 3. X-ray diffraction (XRD) patterns acquired from (a) the aluminum side and (b) the copper side of a fractured welding sample at an amplitude of $22.5 \mu \mathrm{m}$ and a weld time of $0.9 \mathrm{~s}$.

The interface temperatures measured at the weld center, as a function of the vibration amplitude from 20 to $25 \mu \mathrm{m}$, are shown in Figure 4a. Clearly, the growth rate of the interface temperature increased with the vibration amplitude. For the amplitude of $22.5 \mu \mathrm{m}$, the maximum interface temperature at the welding time of $1 \mathrm{~s}$ was approximately $633 \mathrm{~K}$, which could not satisfy the requirement of melting the welded coupons. However, it was sufficient to cause a dramatic decrease of the welded coupons' yield stress and generate the intermetallic compound between the base materials [3]. Significantly, the local melting at the periphery of $\mathrm{Cu} / \mathrm{Al}$ joints was also observed, which will be addressed in the following.
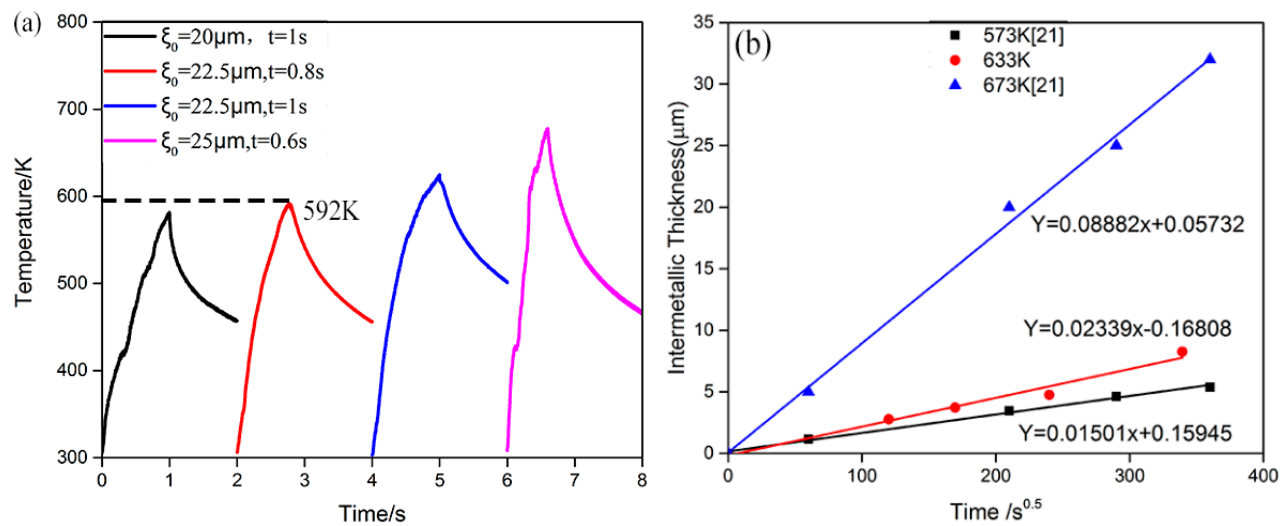

Figure 4. (a) Interfacial temperature measured during ultrasonic spot welding (USW) for various amplitudes; (b) Changes in the intermetallic layer thickness with the annealing time and temperature.

To understand the intermetallic growth, isothermal treatments were performed on the $\mathrm{Cu} / \mathrm{Al}$ joints that were gently welded with an ultrasonic welder. The isothermal treatments were conducted on the pre-welded samples at $633 \mathrm{~K}$ for 1-32 h. The IMC thickness measurements for the isothermal heat treatment at $633 \mathrm{~K}$ were compared to the results obtained by Lee et al. [21], as shown in Figure $4 \mathrm{~b}$. It is obvious that the increase in the average IMC thickness with the annealing time conforms to the parabolic growth law. The relationship between the intermetallic thickness and the annealing time can be expressed as

$$
l^{2}=D t
$$

where $t$ is the heat treatment time and $D$ is the growth rate constant. $l$ is the intermetallic thickness. The relationship between the growth rate constant $(D)$ and the annealing temperature $(T)$ is described as

$$
D=D_{0} \exp \left(-\frac{Q}{R T}\right)
$$


where $D_{0}$ is the correlation coefficient, $Q$ is the activated energy, $R$ is Boltzmann's constant $\left(R=8.314 \mathrm{Jmol}^{-1} \mathrm{~K}^{-1}\right)$ and $T$ is the absolute temperature.

Based on the thermal cycles, the predicted value of the intermetallic thickness could be calculated through the discreet time integration with the rate constant acquired under isothermal annealing treatments, as given by

$$
d l=\frac{D}{2 l} d t
$$

Figure 5a shows the growth rate of the intermetallic thickness at the weld center as a function of the vibration amplitude. For the amplitude of $25 \mu \mathrm{m}$, a continuous intermetallic layer was first observed at the welding time of $0.4 \mathrm{~s}$, which was earlier than the $0.6 \mathrm{~s}$ observed at the amplitude of $22.5 \mu \mathrm{m}$ and $0.8 \mathrm{~s}$ at the amplitude of $20 \mu \mathrm{m}$. The reasons for the acceleration of the intermetallic layer formation at a greater amplitude were as follows: first, the shear stain rate in ultrasonic welding increased with the amplitude [16]. The vacancy concentration in copper increased more significantly at the greater stain rate, thus accelerating the diffusion through the welding interface [22]. Second, a greater vibration amplitude generated more frictional energy, resulting in the more rapid increase of the interface temperature. The higher interface temperature accelerated the diffusion between the base materials.
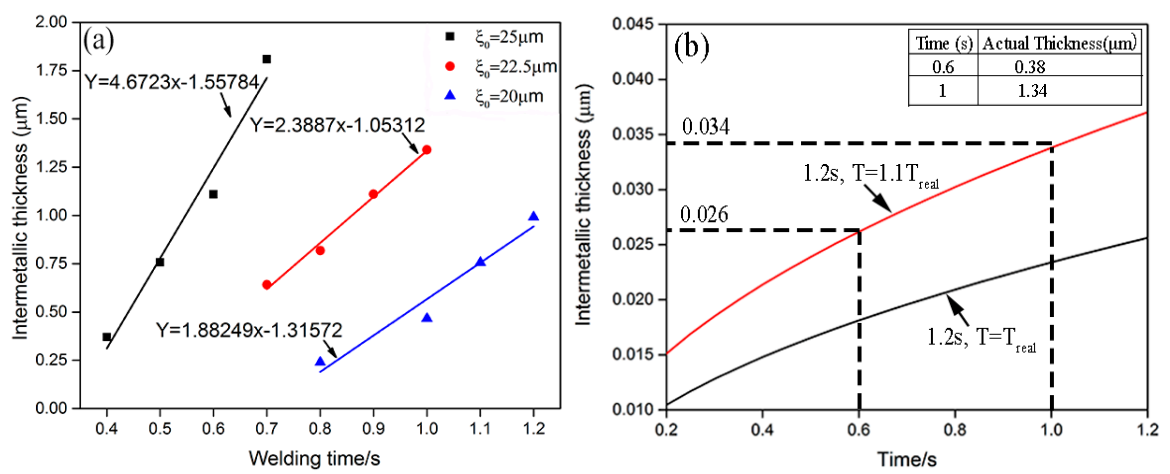

Figure 5. (a) Changes in the intermetallic thickness with welding time at various amplitude levels; (b) Predicted thickness of the intermetallic layer for $1 \mathrm{~s}$ of weld, with and without considering thermal measurement errors $\left(Q=72.013 \mathrm{~kJ} \cdot \mathrm{mol}^{-1}[23]\right)$.

To understand if any systematic change was obvious in the interfacial reaction kinetics during ultrasonic spot welding, the parabolic growth law was used in the kinetic model. The growth rate of the intermetallic layer during the welding process and the predicted value obtained by the kinetic model were compared. Figure $5 \mathrm{~b}$ shows the predicted thickness as a function of welding time at various interface temperatures. However, the predicted value was calculated without considering the growth of the intermetallic layer in the cooling process. It was discovered that the predicted thickness reached only $\sim 4.8 \%$ of the real thickness of the intermetallic layer generated by ultrasonic spot welding.

Moreover, the error was an inevitable part of the interface temperature measurements during the rapid welding process because of inaccuracies in the position and thermal lag values. Consequently, the predicted value was also calculated, considering the $10 \%$ negative error during the interface temperature measurements. For example, for the weld duration of $1 \mathrm{~s}$, a $10 \%$ error in the interface temperature was equivalent to $36^{\circ} \mathrm{C}$ at the amplitude of $22.5 \mu \mathrm{m}$. With the errors consideration in both the temperature measurements and the activation energy, the predicted thickness was only $\sim 6.9 \%$ of the real intermetallic thickness. This might be related to the high-strain-rate plastic deformation during ultrasonic welding. The lattice defects, such as the excess concentration of vacancies, the high density of dislocations and substructures, were generated owing to the severe plastic deformation during ultrasonic welding $[10,22]$. It is well known that the diffusion can be accelerated dramatically by the high concentrations of lattice defects. Significantly, the ratio of the enhanced diffusivity in 
ultrasonic welding to the predicted diffusivity was much smaller than $1.57 \times 10^{5}$ previously examined for the ultrasonic welding of $\mathrm{Al}-\mathrm{Zn}$ where a continuous intermetallic layer was not formed [22]. It was implied that the formation of lattice defects was likely to have the greatest influence on the nucleation of IMC islands in the early stages of ultrasonic welding. Because the nucleation rate was dominated by the inter-diffusion across the welding interface $[13,19]$, the spreading of the IMC islands could also be accelerated owing to the interface-controlled diffusion between the intermetallics and the matrix [13]. However, the growth rate would be controlled by the diffusion through the IMC layer as soon as the continuous reaction layer was formed. The effects of lattice defects generated by the severe plastic deformation on the diffusion were significantly suppressed by the non-deforming intermetallic layer. However, since the main IMC phase $\left(\mathrm{CuAl}_{2}\right)$ was of tetragonal structure, including a lot of structural defects, such as grain boundary and dislocations [24], it was unlikely that the effects were completely eliminated in the $\mathrm{Cu}$ or $\mathrm{Al}$ matrix junction subsequently to the reaction layer becoming continuous. Therefore, it was found that the growth rate of the intermetallic thickness was still more than 14 times greater than the rate acquired from the parabolic growth predictions made with growth rate constant, as obtained from the static heat treatments condition.

\subsection{Mechanical Performance}

Figure 6a shows the lap shear tensile strength of the $\mathrm{Cu} / \mathrm{Al}$ joints as a function of welding time at various amplitudes. The tensile strength of the $\mathrm{Cu} / \mathrm{Al}$ joints first increased and then decreased with welding time at a constant amplitude. For the amplitude of $22.5 \mu \mathrm{m}$, the effective bonding area increased with welding time from 0.2 to $0.8 \mathrm{~s}$, as shown in Figure 7 . Moreover, the tensile strength increased with the effective bonded area. The partial mechanical interlocking and a thin intermetallic reaction layer contributed to the improvement of the tensile strength [2,3]. Nevertheless, it is well known that the excessively thick intermetallic layer that is produced during ultrasonic spot welding at the faying interface results in the decreased tensile strength of the $\mathrm{Cu} / \mathrm{Al}$ joints [2]. When the amplitude was $20 \mu \mathrm{m}$, the maximum tensile strength reached $67 \mathrm{MPa}$. Also, the corresponding intermetallic thickness was $0.94 \mu \mathrm{m}$, as shown in Figure 5a. For the amplitudes of 22.5 and $25 \mu \mathrm{m}$, the maximum tensile strength was approximately $75 \mathrm{MPa}$. The corresponding intermetallic thicknesses were 0.98 and $0.78 \mu \mathrm{m}$ respectively, as shown in Figure 5a. It was found that the lap shear tensile strength of the $\mathrm{Cu} / \mathrm{Al}$ joints decreased when the thickness of the intermetallic layer exceeded $1 \mu \mathrm{m}$ at various amplitudes. Besides, the $\mathrm{Cu} / \mathrm{Al}$ joint failure always occurred along the interface instead of in a nugget pull-out mode, as previously reported for $\mathrm{Cu} / \mathrm{Al}[3,20]$. It was thus more likely that the copper substrate suffered from the higher strain rate deformation than the aluminum substrate. The hardness measured at the interface increased with welding time, as shown in Figure $6 \mathrm{~b}$. This was ascribed to the increase in the intermetallic thickness at the welding line.
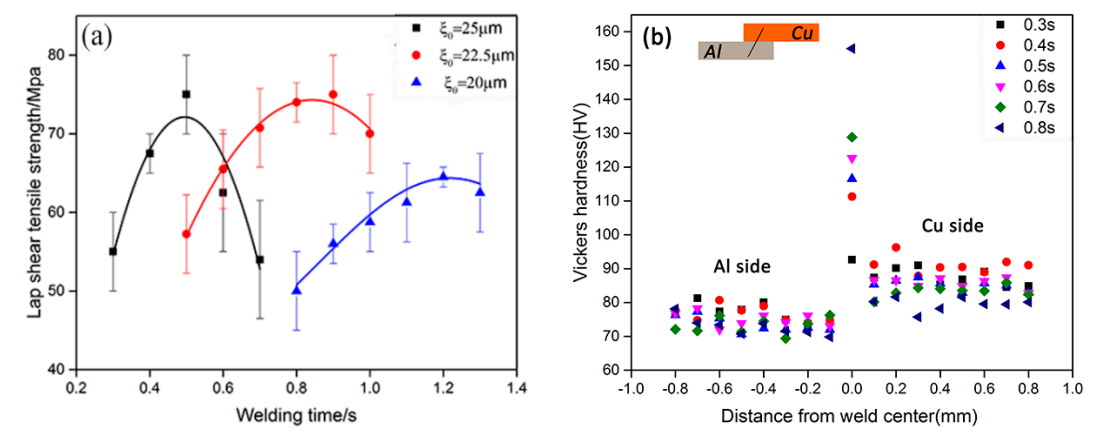

Figure 6. Mechanical performance of ultrasonic welded joints, (a) lap shear test results, (b) Vickers hardness measured at the amplitude of $25 \mu \mathrm{m}$. 


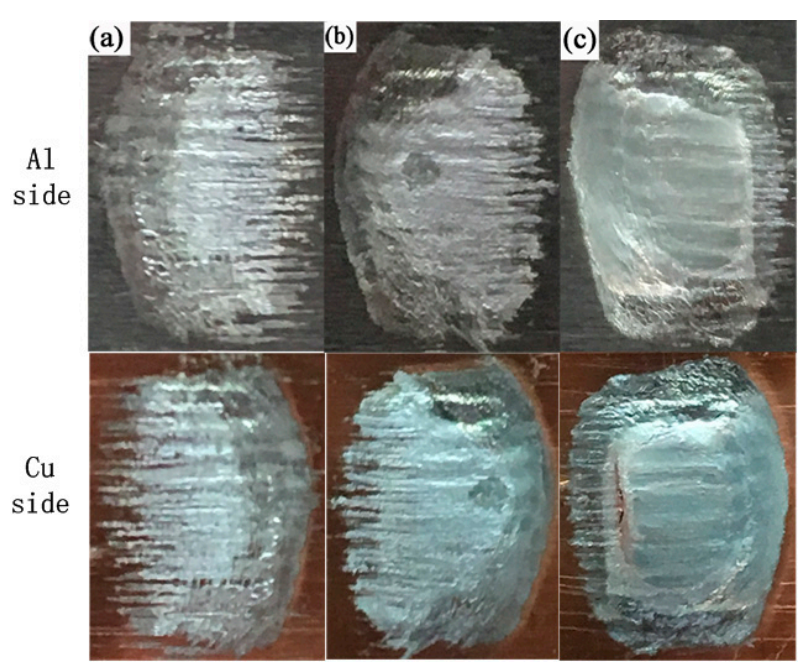

Figure 7. Fracture surface of $\mathrm{Cu} / \mathrm{Al}$ joints made at (a) $0.2 \mathrm{~s}$, (b) $0.5 \mathrm{~s}$ and (c) $0.8 \mathrm{~s}$, for the amplitude of $22.5 \mu \mathrm{m}$.

\subsection{Welding Defects}

Figure 8 shows the scanning electron microscopy images obtained at the edge of the welding region for various amplitudes (Figure $8 \mathrm{a}-\mathrm{g}$ ) and their corresponding output ultrasonic power curves (Figure 8h). It was observed that the crack occurred in the copper side at the periphery of the welding region. For the amplitude of $20 \mu \mathrm{m}$, the heterogeneous region was discovered at the welding time of $1.1 \mathrm{~s}$, as shown in Figure 8a. Subsequently, the crack occurred in the copper side at the welding time of $1.2 \mathrm{~s}$. For the amplitude of $22.5 \mu \mathrm{m}$, the crack was initiated at $0.8 \mathrm{~s}$, as shown in Figure 8c. For the amplitude of $25 \mu \mathrm{m}$, the crack was first observed at $0.4 \mathrm{~s}$, as indicated in Figure 8f. The solidified microstructure was observed with the crack and was composed of the gray and black phases. Regions A, E and G consisted of the gray phase, and Regions C, D and F consisted of the black phase. Obviously, these microstructures were distinguishable from the base metals. The test results of the atom obtained by EDS showed that the gray phase in regions $\mathrm{A}, \mathrm{E}$ and $\mathrm{G}$ consisted of $68.21 \mathrm{Al}-31.79 \mathrm{Cu}, 69.1 \mathrm{AL}-30.9 \mathrm{Cu}$ and $69.79 \mathrm{Al}-30.21 \mathrm{Cu}$, respectively. The black phase in regions $\mathrm{C}, \mathrm{D}$ and $\mathrm{F}$ consisted of $96.9 \mathrm{Al}-3.1 \mathrm{Cu}, 96.93 \mathrm{Al}-3.07 \mathrm{Cu}$ and 95.21 $\mathrm{Al}-4.79 \mathrm{Cu}\left(\right.$ at \%), respectively. According to the $\mathrm{Cu} / \mathrm{Al}$ binary diagram, this implied that $\mathrm{CuAl}_{2}$ was the major phase in regions $\mathrm{A}, \mathrm{E}$ and $\mathrm{G}$, whereas regions $\mathrm{C}, \mathrm{D}$ and $\mathrm{F}$ consisted of $\alpha-A l$. This finding suggested that local melting occurred at the periphery of the $\mathrm{Cu} / \mathrm{Al}$ joints according to the eutectic reaction, $\alpha-A l+\theta \rightarrow L$. However, for the amplitude of $22.5 \mu \mathrm{m}$, the peak temperature was measured as $593 \mathrm{~K}$ at the welding time of $0.8 \mathrm{~s}$, which was significantly lower than the temperature of the eutectic reaction. It was more likely that the melting point was depressed by the high-strain-rate ultrasonic deformation [22]. Besides, A. Panteli reported that the melting point could also be depressed by the presence of additional elements [13]. Significantly, the temperature was measured at the center of the nugget, whereas the local melting occurred at its periphery. The copper matrix underwent greater plastic deformation and stress at the periphery of the nugget [25]. The frictional energy intensity at the periphery of the welding region was always maximum [26]. The maximum frictional energy intensity led to the maximum instantaneous elevated temperature, and localized melting might occur. For the amplitude of $20 \mu \mathrm{m}$, the local melting occurred at $1.1 \mathrm{~s}$ and was included in the copper layer, but the crack was not observed. With the increase in welding time, the local melting spread in the copper layer and subsequently the crack occurred at $1.2 \mathrm{~s}$. It was concluded that the local melting induced the generation of cracks. Besides, since the interface temperature increased more rapidly at a greater amplitude, the increasing amplitude led to the earlier generation of cracks in the $\mathrm{Cu}$ side. 

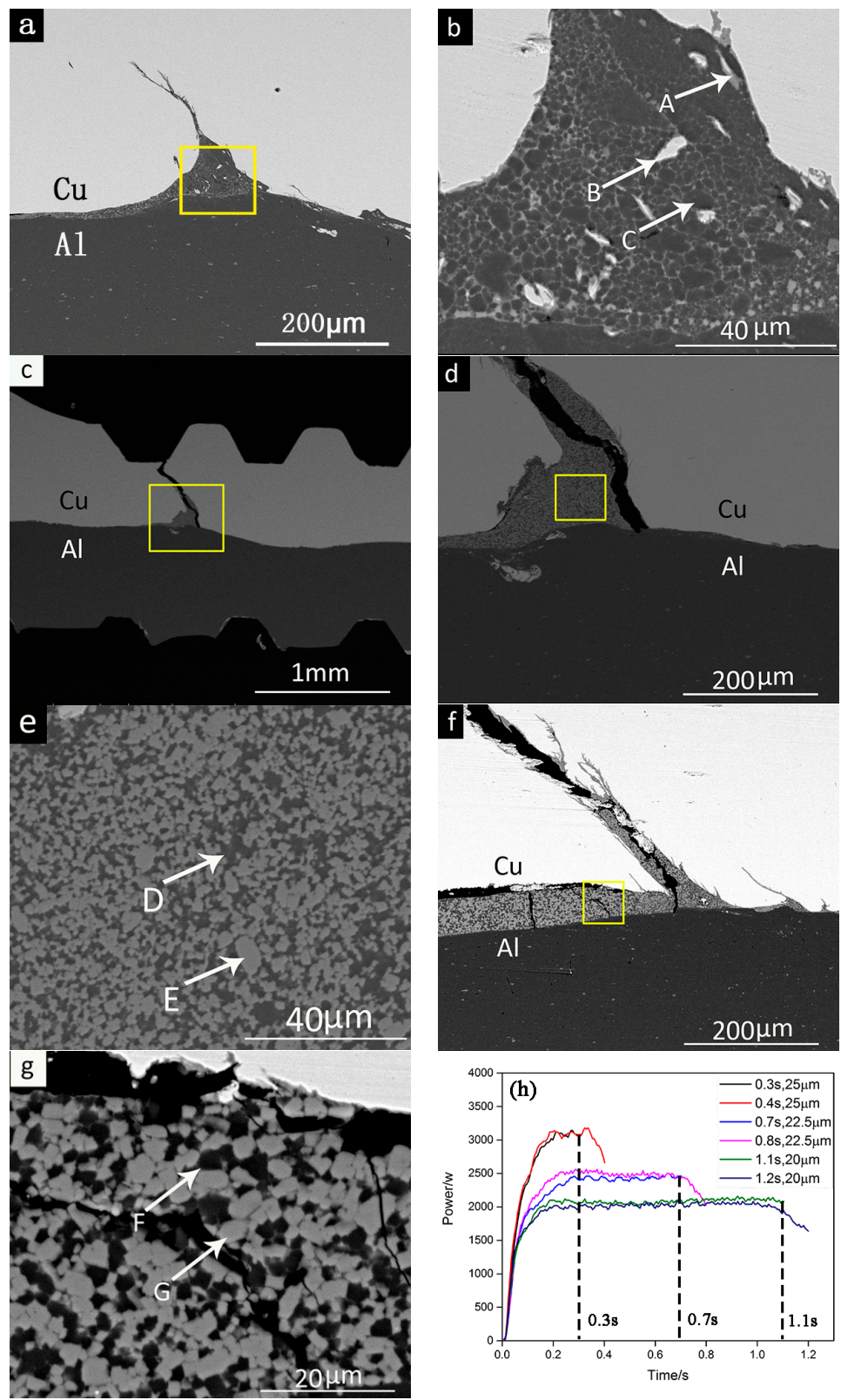

Figure 8. SEM images obtained at the edge of the nugget, (a) at the welding time of $1.1 \mathrm{~s}$ for the amplitude of $20 \mu \mathrm{m}$, (c) at $0.8 \mathrm{~s}$ for $22.5 \mu \mathrm{m}$, and (f) at $0.4 \mathrm{~s}$ for $25 \mu \mathrm{m}$. (b) Magnified view of the image in the rectangular frame in (a); (d) Magnified view of the image in the rectangular frame in (c); (e) Further magnification of the image in the rectangular frame in (d); (g) Magnified view of the image in the rectangular frame in (f). (h) Ultrasonic power output curves at various amplitudes.

Figure $8 \mathrm{~h}$ shows the ultrasonic power curves before and after the generation of the crack in the copper side at various amplitude levels, as obtained by the self-monitoring system. A significant decline of the ultrasonic power curve was observed upon the formation of a crack. The relationship between the ultrasonic power and the sonotrode force can be expressed as:

$$
P=F_{s} * v_{\text {avg }}
$$

where $F_{s}$ is the sonotrode force and $v_{\text {avg }}$ is the average vibration rate. The vibration displacement can be written as [22]:

$$
\xi(t)=\xi_{0} \sin (\omega t), \quad f=|\omega| / 2 \pi \quad(f=20 \mathrm{kHz})
$$


where $\xi(t)$ is the vibration displacement, $\xi_{0}$ is the amplitude and $f$ is the vibration frequency. Solving the differential equation for the vibration displacement, the vibration rate can be described as

$$
\dot{\xi}(t)=\frac{d \xi(t)}{d t}=\omega \xi_{0} \cos (\omega t)
$$

The acceleration can be obtained by the differentiation of the vibration rate Equation (6). Thus, $\ddot{\xi}(t)$ is given by

$$
\ddot{\xi}(t)=-\omega^{2} \xi_{0} \sin (\omega t)
$$

The average vibration rate can be calculated as

$$
v_{\text {avg }}=\frac{1}{T} \int_{0}^{T}\left|\omega * \xi_{0} \cos (\omega t)\right| d t=4 * \xi_{0} * f
$$

where $T$ is the period of vibration. Substituting Equation (8) into Equation (4), the ultrasonic power can be described as

$$
P=F_{s} * 4 * \xi_{0} * f
$$

An overview of the forces acting at the sonotrode is shown in Figure 9. The relationship among the sonotrode force $\left(F_{s}\right)$, the lateral deformation resistance $\left(F_{L}\right)$ and the interface friction force $\left(F_{I}\right)$ is derived from Newton's second law of motion and can be expressed as

$$
\ddot{m} \ddot{\xi}=F_{S}-F_{I}-F_{L}
$$

Therefore, the sonotrode force can be described as

$$
F_{s}=F_{I}+F_{L}+m \ddot{\ddot{\xi}}
$$

where $m$ is the mass of sonotrode.

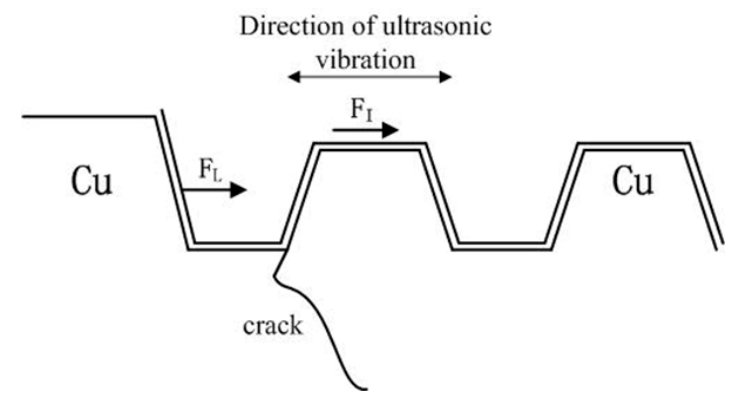

Figure 9. Overview of the forces acting at the sonotrode.

Based on Equation (10), it was found that the ultrasonic power was closely associated with the sonotrode force, the amplitude and the vibration frequency, which is $20 \mathrm{kHz}$. According to Equation (12), once the crack in the copper side was generated, the lateral deformation force $\left(F_{L}\right)$ was released. Subsequently, a smaller sonotrode force $\left(F_{s}\right)$ was necessary to achieve the ultrasonic vibration at the same amplitude. Also, a feedback system controlled the power output to maintain the welding tip in the high-frequency cyclical movement at the designated vibration amplitude. Therefore, it was concluded that a significant reduction of the sonotrode force $\left(F_{S}\right)$, caused by the generation of a crack in the copper side, resulted in a remarkable decline of the power curve. 


\section{Conclusions}

In the present work, the effects of the vibration amplitude on the interface reaction and mechanical performance of the $\mathrm{Cu} / \mathrm{Al}$ joints were studied. The valuable conclusions stemming from this study are as follows:

1. The growth rates of the intermetallic thickness increased with the vibration amplitude during ultrasonic welding.

2. The tensile strength of the $\mathrm{Cu} / \mathrm{Al}$ joints first increased and then decreased with the welding time at a constant amplitude. The critical thickness of the IMC layer, for the increasing lap tensile strength at the amplitudes of 20 and $22.5 \mu \mathrm{m}$, was $\sim 1 \mu \mathrm{m}$, whereas the critical thickness was $\sim 0.78 \mu \mathrm{m}$ at the amplitude of $25 \mu \mathrm{m}$.

3. The eutectic reaction, $\alpha-A l+\theta \rightarrow L$, occurred at the periphery of the nugget. Subsequently, the local melting induced the generation of a crack. A more rapid increase in the interface temperature led to the earlier generation of a crack at a greater amplitude. Moreover, the significant reduction of the sonotrode force $\left(F_{s}\right)$, due to the generation of a crack in the copper side, resulted in a remarkable decline of the ultrasonic power curve.

4. The variation of ultrasonic power could potentially be beneficial for obtaining a sound joint by avoiding the generation of a crack. According to the lap shear test results and the ultrasonic power output curve, the optimal parameters were a welding time of $0.7 \mathrm{~s}$ and an amplitude of $22.5 \mu \mathrm{m}$.

Acknowledgments: The study was funded by the National Natural Science Foundation of China (No. 51175184).

Author Contributions: Jian Liu conceived and designed the experiments; Jian Liu performed the experiments; Jian Liu analyzed the data; Jian Liu wrote the paper; Biao Cao supervised the manuscript. Jingwei Yang oversaw the paper.

Conflicts of Interest: The authors declare no conflict of interest.

\section{References}

1. Balasundaram, R.; Patel, V.K.; Bhole, S.D.; Chen, D.L. Effect of zinc interlayer on ultrasonic spot welded aluminum-to-copper joints. Mater. Sci. Eng. A 2014, 607, 277-286. [CrossRef]

2. Yang, J.W.; Cao, B.; He, X.C.; Luo, H.S. Microstructure evolution and mechanical properties of $\mathrm{Cu}-\mathrm{Al}$ joints by ultrasonic welding. Sci. Technol. Weld. Join. 2014, 19, 500-504. [CrossRef]

3. Zhao, Y.Y.; Li, D.; Zhang, Y.S. Effect of welding energy on interface zone of Al-Cu ultrasonic welded joint. Sci. Technol. Weld. Join. 2013, 18, 354-360. [CrossRef]

4. Ni, Z.L.; Zhao, H.J.; Mi, P.B.; Ye, F.X. Microstructure and mechanical performances of ultrasonic spot welded $\mathrm{Al} / \mathrm{Cu}$ joints with Al 2219 alloy particle interlayer. Mater. Des. 2016, 92, 779-786. [CrossRef]

5. Tan, C.W.; Jiang, Z.G.; Li, L.Q.; Chen, Y.B.; Chen, X.Y. Microstructural evolution and mechanical properties of dissimilar Al-Cu joints produced by friction stir welding. Mater. Des. 2013, 51, 466-473. [CrossRef]

6. Zhang, W.; Shen, Y.F.; Yan, Y.F.; Guo, R. Dissimilar friction stir welding of $6061 \mathrm{Al}$ to T2 pure Cu adopting tooth-shaped joint configuration: Microstructure and mechanical properties. Mater. Sci. Eng. A 2017, 690, 355-364. [CrossRef]

7. Sahu, P.K.; Pal, S.; Pal, S.K.; Jain, R. Influence of plate position, tool offset and tool rotational speed on mechanical properties and microstructures of dissimilar $\mathrm{Al} / \mathrm{Cu}$ friction stir welding joints. J. Mater. Process. Technol. 2016, 235, 55-67. [CrossRef]

8. Mehta, K.P.; Badheka, V.J. Influence of tool pin design on properties of dissimilar copper to aluminum friction stir welding. Trans. Nonferr. Met. Soc. 2017, 27, 36-54. [CrossRef]

9. Ni, Z.L.; Ye, F.X. Dissimilar joining of aluminum to copper using ultrasonic welding. Mater. Manuf. Process. 2016, 31, 2091-2100. [CrossRef]

10. Bakavos, D.; Prangnell, P.B. Mechanisms of joint and microstructure formation in high power ultrasonic spot welding 6111 aluminium automotive sheet. Mater. Sci. Eng. A 2010, 527, 6320-6334. [CrossRef] 
11. Yang, J.W.; Cao, B. Investigation of resistance heat assisted ultrasonic welding of 6061 aluminum alloys to pure copper. Mater. Des. 2015, 74, 19-24. [CrossRef]

12. Mehta, K.P.; Badheka, V.J. Effects of tilt angle on the properties of dissimilar friction stir welding copper to aluminum. Mater. Manuf. Process. 2016, 31, 255-263. [CrossRef]

13. Panteli, A.; Robson, J.D.; Brough, I.; Prangnell, P.B. The effect of high strain rate deformation on intermetallic reaction during ultrasonic welding aluminium to magnesium. Mater. Sci. Eng. A 2012, 556, 31-42. [CrossRef]

14. Haddadi, F. Rapid intermetallic growth under high strain rate deformation during high power ultrasonic spot welding of aluminium to steel. Mater. Des. 2015, 66, 459-472. [CrossRef]

15. Shakil, M.; Tariq, N.H.; Ahmad, M.; Choudhary, M.A.; Akhter, J.I.; Babu, S.S. Effect of ultrasonic welding parameters on microstructure and mechanical properties of dissimilar joints. Mater. Des. 2014, 55, 263-273. [CrossRef]

16. Patel, V.K.; Bhole, S.D.; Chen, D.L. Influence of ultrasonic spot welding on microstructure in a magnesium alloy. Scr. Mater. 2011, 65, 911-914. [CrossRef]

17. Bates, P.J.; MacDonald, J.; Sidiropoulos, V.; Kontopoulou, M. Comparison of experimental and analytical vibration welding meltdown-time profiles for nylon 66 and polypropylene. Polym. Eng. Sci. 2005, 45, 789-797. [CrossRef]

18. Mirza, F.A.; Macwan, A.; Bhole, S.D.; Chen, D.L.; Chen, X.G. Effect of welding energy on microstructure and strength of ultrasonic spot welded dissimilar joints of aluminum to steel sheets. Mater. Sci. Eng. A 2016, 668, 73-85. [CrossRef]

19. Robson, J.; Panteli, A.; Prangnell, P.B. Modelling intermetallic phase formation in dissimilar metal ultrasonic welding of aluminium and magnesium alloys. Sci. Technol. Weld. Join. 2012, 17, 447-453.

20. Fujii, H.T. Microstructural evolution in dissimilar joint of al alloy and $\mathrm{Cu}$ during ultrasonic welding. Mater. Sci. Forum 2014, 783-786, 2747-2752. [CrossRef]

21. Lee, W.B.; Bang, K.S.; Jung, S.B. Effects of intermetallic compound on the electrical and mechanical properties of friction welded $\mathrm{Cu} / \mathrm{Al}$ bimetallic joints during annealing. J. Alloys Compd. 2005, 390, 212-219. [CrossRef]

22. Gunduz, I.E.; Ando, T.; Shattuck, E.; Wong, P.Y.; Doumanidis, C.C. Enhanced diffusion and phase transformations during ultrasonic welding of zinc and aluminum. Scr. Mater. 2005, 52, 939-943. [CrossRef]

23. Braunovic, M.; Alexandrov, N. Intermetallic compounds at aluminum-to-copper electrical interfaces: Effect of temperature and electric current. IEEE Trans. Compon. Packag. Manuf. Technol. Part A 1994, 17, 78-85. [CrossRef]

24. Chen, C.Y.; Hwang, W.S. Effect of annealing on the interfacial structure of aluminum-copper joints. Mater. Trans. 2007, 48, 1938-1947. [CrossRef]

25. Hang, C.J.; Wang, C.Q.; Mayer, M.; Tian, Y.H.; Zhou, Y.; Wang, H.H. Growth behavior of Cu/Al intermetallic compounds and cracks in copper ball bonds during isothermal aging. Microelectron. Reliab. 2008, 48, 416-424. [CrossRef]

26. Ding, Y.; Kim, J.K.; Tong, P. Numerical analysis of ultrasonic wire bonding: Effects of bonding parameters on contact pressure and frictional energy. Mech. Mater. 2006, 38, 11-24. [CrossRef]

(c) 2017 by the authors. Licensee MDPI, Basel, Switzerland. This article is an open access article distributed under the terms and conditions of the Creative Commons Attribution (CC BY) license (http:/ / creativecommons.org/licenses/by/4.0/). 